\title{
DINÂMICA EROSIVA DE PROCESSOS TROPICAIS: TRÊS DÉCADAS DA EROSÃO CHITOLINA
}

\author{
Karla Maria Silva de Faria ${ }^{(a)}$, Gervásio Barbosa Soares Neto ${ }^{(b)}$ João Vitor Silva Costa ${ }^{(\mathrm{c}),}$ \\ Manuel Eduardo Ferreira ${ }^{(d)}$ \\ (a) Laboratório de Geomorfologia, Pedologia e Geografia Física/Instituto de Estudos Sócio-Ambientais, \\ Universidade Federal de Goiás, karla_faria@ufg.br \\ (b) Instituto Federal de Brasília, Campus Riacho Fundo, gervasio.neto@ifb.edu.br \\ (c) Laboratório de Processamento de Imagens e Geoprocessamento/Instituto de Estudos Sócio-Ambientais, \\ Universidade Federal de Goiás, joaovsc17@gmail.com, \\ (d) Laboratório de Processamento de Imagens e Geoprocessamento/Instituto de Estudos Sócio-Ambientais, \\ Universidade Federal de Goiás. Bolsista de produtividade pelo CNPq. mferreira.geo@gmail.com
}

Eixo: Uso e ocupação das terras e legislação ambiental

\begin{abstract}
Resumo
A erosão Chitolina, destaca-se em Goiás por apresentar dinâmica evolutiva complexa e ser a maior erosão no lado goiano na emblemática bacia do Araguaia. Em regiões agrícolas, o monitoramento da evolução desses processos é fundamental para as estratégias de projetos de recuperação. O objetivo do trabalho foi avaliar à dinâmica erosiva evolutiva da erosão Chitolina, considerando os dados do cadastro do processo erosivo realizado em 1998 e a realização de campo com uso de veículo aéreo não tripulado (VANT) em 2016. Os resultados constaram que o processo encontra-se estabilizado com ausência de desenvolvimento remontante, abertura de novas ramificações, o leito da erosão está sendo entulhado com material que se rompe dos taludes e não há curso definido de drenagem; alguns piping na porção média da feição. A utilização do VANT no mapeamento e monitoramento desses processos otimiza recursos físicos e humanos no cadastro e dados automatizados facilmente validados em campo.
\end{abstract}

Palavras chave: Voçoroca Chitolina; Degradação do solo; mapeamento; VANT.

\section{Introdução}

Dentre os diversos impactos ambientais associados às atividades agropecuárias, a análise e a avaliação dos processos erosivos antrópicos comumente ganha destaque, por implicar no comprometimento da qualidade hídrica, perda de solo agricultável e ameaças ao equilíbrio ecossistêmico (HELFER et al., 2003; CARVALHO et al., 2006). Segundo a FAO (2015), os processos erosivos eliminam por ano entre 25 e 40 bilhões de toneladas de solo no mundo, o que implica diretamente na produtividade das culturas e em outras funções do solo, além de comprometimento dos cursos hidrográficos.

A erosão é um processo evolutivo das paisagens, mas em regiões tropicais ela se intensifica, dada a concentração e intensidade das chuvas em áreas submetidas a ações de desmatamentos e com parâmetros morfográficos e morfológicos favoráveis. O processo evolui nos estágios laminares (escoamento difuso da água) e lineares (concentração de linhas de fluxo das águas superficiais e 
OS DESAFIOS DA GEOGRAFIA FÍSICA NA FRONTEIRA DO CONHECIMENTO

Instituto de Geociências - Unicamp

Campinas - SP

28 de Junho à 02 de Julho de 2017

subsuperficiais), podendo gerar sulcos, ravinas e voçorocas, por vezes evolutivos entre si, nessa ordem (INFANTI; FORNASARI, 1998; GUERRA et al., 2005; LEPSCH, 2010).

Os estudos conduzidos na região das nascentes do rio Araguaia, no estado de Goiás, constataram diversos impactos ambientais, como desmatamentos (FARIA; CASTRO, 2007; CABACINHA; CASTRO, 2009) e arenização (SILVA, 2006). Porém, a alta concentração de processos erosivos lineares, do tipo ravina e voçoroca, destacou-se em função da alta suscetibilidade do terreno e da associação ao rápido processo de ocupação de topos de chapada e áreas rebaixadas, que se vincularam à expansão da fronteira agrícola (CASTRO et al., 2004, CASTRO, 2005).

No final da década de 1990, os estudos foram realizados com base em fotos aéreas e imagens de satélite Landsat, vinculados a dois projetos financiados pela Secretaria de Ciência e Tecnologia do estado de Goiás e pelo CNPq (CASTRO, 2005). Na década de 2000, os estudos prosseguiram vinculados também ao projeto Recomposição ambiental na área das nascentes do rio Araguaia, que visava a implementação de práticas adequadas de controle da erosão (FUNDAÇÃO EMAS, 1998), com financiamento do Ministério de Ciência e Tecnologia (atual MCTI). Paralelamente, levantamentos de solos, acompanhados de ensaios de infiltração e de levantamentos geofísicos visando entender o comportamento físico-hídrico dos solos, do lençol freático e do substrato também foram realizados (BOULET et al., 2001; MOURA; SHIRAIWA, 2003; SHIRAIWA et al., 2003). Os resultados desses projetos e seus desdobramentos acadêmicos, científicos e de gestão pública estadual permitiram a elaboração do Atlas Geoambiental das Nascentes do rio Araguaia e Araguainha e ao Plano Diretor de Controle da Erosão nas Nascentes do rio Araguaia e Araguainha (CASTRO et al., $2004 \mathrm{a}, \mathrm{b}$ ). Os procedimentos empregados por esses pesquisadores proporcionaram avanços no conhecimento do comportamento dessas feições e na própria dinâmica do processo erosivo na região (MARTINS, et al., 2006), além de terem corroborado teorias consolidadas sobre a fenomenologia, sobretudo para regiões tropicais da época, expresso por vários autores, dentre eles Salomão (1999).

Os processos erosivos expressivos foram identificados principalmente próximos à região das nascentes do Araguaia e nas áreas rebaixadas de relevos concavizados pedimentares, situados abaixo das cimeiras locais (Serra de Caiapó e Morro Vermelho). Inicialmente, Silva et al. (2001) identificaram e avaliaram a presença de mais de 90 voçorocas de grande porte na região ( $\geq 300 \mathrm{~m}$ de extensão do eixo maior). Em seguida, a avaliação das erosões por diversas instituições, como a Fundação Emas, CELG/METAGO, UFG, UFMT, destacaram a feição erosiva denominada de "Voçoroca Chitolina" próxima ao Parque Estadual das Emas, em função do seu grande porte e em ritmo acelerado de evolução. Esta voçoroca fora cadastrada em 1998 pela CELG/CPRM (1998; CASTRO; XAVIER; BARBALHO, 2004). Medidas de controle foram implementadas nessa voçoroca, porém sem muito sucesso; atualmente, não se sabe como está sua dinâmica, se ainda muito ativa ou em estabilização. 


\section{OS DESAFIOS DA GEOGRAFIA FÍSICA NA FRONTEIRA DO CONHECIMENTO \\ Instituto de Geociências - Unicamp \\ Campinas - SP \\ 28 de Junho à 02 de Julho de 2017}

Nos últimos anos, considerando os avanços nas técnicas de mapeamento por sensoriamento remoto, em especial com o advento das plataformas aéreas não tripuladas, também conhecidas como VANT (Veículo Aéreo Não Tripulado), ou Drone, o monitoramento de processos erosivos vem sendo amplamente beneficiado, sobretudo pela elevada resolução espacial obtidas por imagens aéreas. Além de mosaicos ortorretificados, o VANT propicia a geração de Modelos Digitais de Superfície (MDS) e de Terreno (MDT), fundamentais para se reconhecer com precisão a área afetada pelas erosões e seus usos, bem como para se planejar a melhor forma de recuperação ambiental dessas áreas de contribuição.

A aplicação do VANT no monitoramento de processos erosivos, em especial do modelo de asa-fixa empregado neste estudo (com maior autonomia de voo), se constitui numa forma para reduzir as diferenças entre as escalas de campo e as do satélite, por meio de fotografias aéreas com elevada resolução espacial e temporal.

Neste sentido, o emprego de um VANT permite mapear e medir a erosão em grande detalhe e precisão (com pixels na casa de centímetros), com uma frequência de monitoramento adequada ao pesquisador ou órgão gestor, além de várias perspectivas (em 3 dimensões, com a fusão do mosaico aerofotogramétrico ao modelo digital de superfície).

Do contrário, isso só poderia ser feito por medições de campo extremamente laboriosas, com estações totais, receptores GNSS com elevada precisão ou com scanners a laser (em campo, ou a bordo de aeronaves - com instrumentos do tipo LIDAR, bastante onerosos até o momento). No entanto, e conforme frisado por D'Oleire-Oltmanns et al. (2012), todos esses sistemas, diferentemente dos VANTs, provavelmente não conseguiriam capturar todas as informações na superfície, devido às dificuldades/risco de acesso aos locais das erosões, falta de visibilidade, ou simplesmente pela logística mais complexa.

Neste contexto, o objetivo deste trabalho é avaliar a dinâmica evolutiva da erosão Chitolina entre 1980 e 2016, com base nos referidos registros históricos e imageamento com VANT. Esta erosão foi selecionada pelo Projeto de Recomposição das Nascentes do Araguaia, no ano de 2004, por apresentar dinâmica evolutiva complexa e ser a maior erosão no lado goiano na alta bacia do rio Araguaia.

\section{Materiais e métodos}

\subsection{Caracterização da área de estudo}

A erosão em estudo localiza-se em uma propriedade rural, no município de Mineiros, no sudoeste goiano, próximo a nascente principal do rio Araguaia e do Parque Nacional das Emas (Figura 1). 


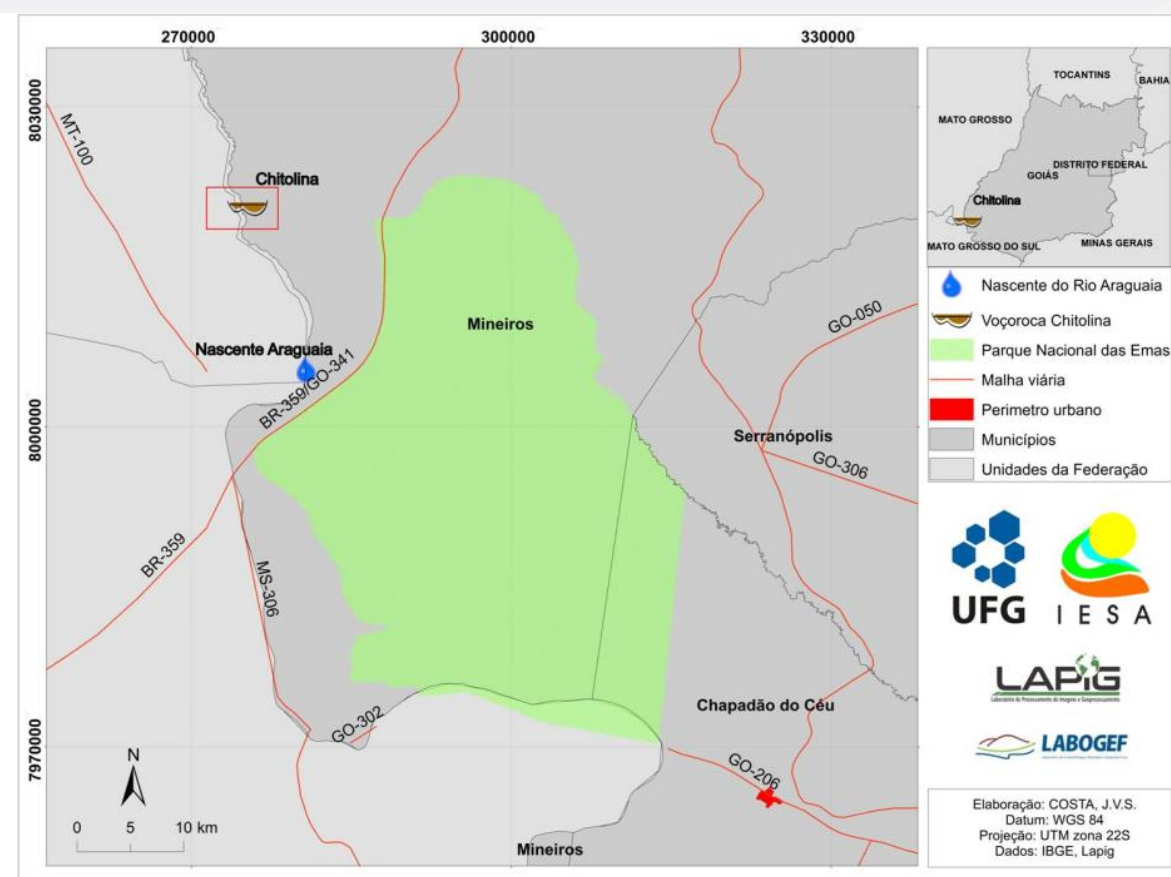

Figura 1. Localização da voçoroca Chitolina a $16 \mathrm{~km}$ da nascente do Rio Araguaia.

A propriedade rural onde se localiza a erosão desenvolve atividades agrícolas que se associam à demanda de mercado da fronteira agrícola (pastagens nas décadas de 1960 e 1970; soja e sorgo nas décadas de 1980 e 1990 e cana-de-açúcar a partir de 2007) (CASTRO; XAVIER; BARBALHO, 2004; TRINDADE, 2015).

A erosão desenvolveu-se em área com predomínio de relevos concavizados, que correspondem aos embaciados amplos que recebem e concentram os fluxos hídricos superficiais e subsuperficiais. Boulet et al. (2001) destacam que as fotos aéreas de 1964 e 1977 indicavam para a área da feição erosiva um talvegue de drenagem e vegetação campestre e pastagens. Tais autores, baseando-se em relatos do proprietário, indicam que a erosão surgiu em meados da década de 1980, após um excepcional episódio de chuva, apresentando inicialmente $150 \mathrm{~m}$ de extensão, $6 \mathrm{~m}$ de profundidade e $8 \mathrm{~m}$ de largura; as análises das imagens Landsat, de 1984 a 1999, indicaram aos pesquisadores que a erosão iniciou-se conectada ao rio Araguaia a jusante, já como voçoroca, tendo evoluído para montante em pouco tempo.

Avaliando a gênese dessa feição, Gomes, Filizola e Boulet (S/D) associaram que a abertura da erosão estava associada à possível sobrealimentação do lençol freático por alta e concentrada precipitação, e pela presença de curvas de nível de contenção associadas ao terraceamento no local, a montante, que aumentaram as taxas de infiltração. A feição erosiva é contornada pelos Latossolos VermelhoAmarelo distróficos a montante e se desenvolveu topograficamente abaixo deste na área de Neossolos Quartzarênicos órticos e hidromórficos, e transiciona para os Gleissolos Melânicos a jusante da ocorrência, adaptando-se a nomenclatura para o atual Sistema Brasileiro de Classificação dos Solos/SiBCS (EMBRAPA, 2013). 


\section{OS DESAFIOS DA GEOGRAFIA FÍSICA NA FRONTEIRA DO CONHECIMENTO \\ Instituto de Geociências - Unicamp \\ Campinas - SP \\ 28 de Junho à 02 de Julho de 2017}

\subsection{Procedimentos metodológicos}

A análise comparada da dinâmica evolutiva dessa erosão envolveu extensa pesquisa bibliográfica e cartográfica sobre o processo, cadastrado oficialmente em 1998. Os dados permitiram a elaboração de um banco de dados com informações referentes às dimensões e comportamento da erosão na década de 1980 e 1990. Foram realizadas visitas de campo nos meses de outubro e novembro de 2016 para levantamento aéreo e avaliações das condições físicas do processo.

Os levantamentos aéreos desta pesquisa foram conduzidos em trabalho de campo no dia 24 de outubro de 2016, empregando-se um Veículo Aéreo Não Tripulado (VANT) da Universidade Federal de Goiás/IESA. O modelo de VANT utilizado foi o Swinglet CAM, fabricado pela empresa suíça Sensefly. O plano de voo foi realizado no programa Emotion (do acrônimo Electronic Monitoring Station), enquanto que o Modelo Digital de Superfície (MDS) e o ortomosaico foram confeccionados no programa Pix4D Mapper.

Sobre o Swinglet CAM, trata-se de um microvant asa-fixa (i.e., abaixo de $25 \mathrm{~kg}$, pesando apenas 500 gramas, já incluindo bateria e a câmera digital do tipo RGB), com propulsor elétrico, projetado para voar em boas condições climáticas, suportando ventos com velocidade inferior a $25 \mathrm{~km} / \mathrm{h}$ (aproximadamente $7 \mathrm{~m} / \mathrm{s}$ ). Sua autonomia de voo é de aproximadamente 35 minutos, com operação totalmente automática desde a decolagem até a aterrissagem, orientado pelo Emotion. A figura 2 ilustra o plano de voo desta pesquisa, sobreposto em imagem de satélite (acervo) fornecida pela Microsoft.

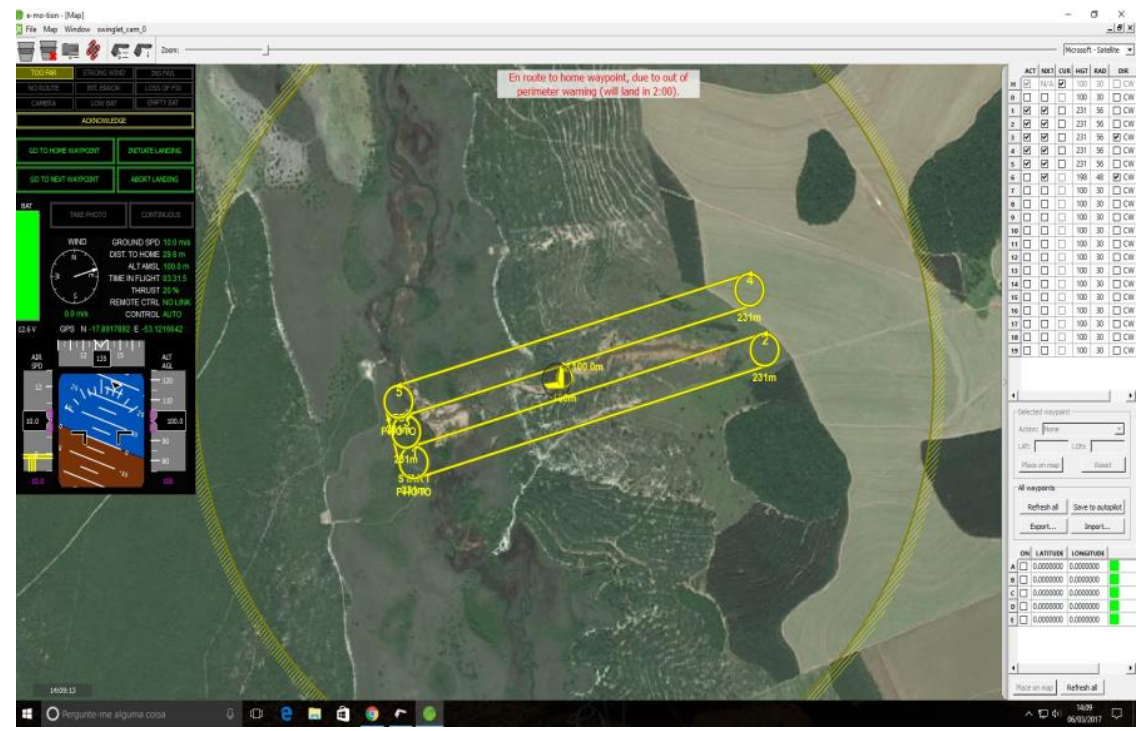

Figura 2- Plano de Voo.

Ainda sobre o plano de voo, este foi realizado em faixas com sobreposição longitudinal e lateral de 60\%, cobrindo uma área total de 111,7 hectares, ao longo de 20 minutos. A altura de voo foi de 165 
metros, com resolução espacial nominal de $5 \mathrm{~cm}$, e real de $7 \mathrm{~cm}$, devido às oscilações da aeronave (esperadas para este tipo de equipamentos).

Os dados obtidos após o processamento dos dados do VANT foram posteriormente comparados com os dados disponibilizados pelo Cadastro da Erosão.

\section{Resultados e discussão}

O cadastro realizado pela CELG/CPRM, em 1998, indica que a "Erosão Chitolina" apresenta as seguintes dimensões: extensão superior a 1.400 metros de eixo longitudinal, 25 metros de profundidade máxima em sua cabeceira; 16 metros em seu percurso médio; 8 metros na sua trajetória final, surgências de água e pipings no trecho médio (onde ela apresenta dinâmica meandrante) (Figura $3)$.

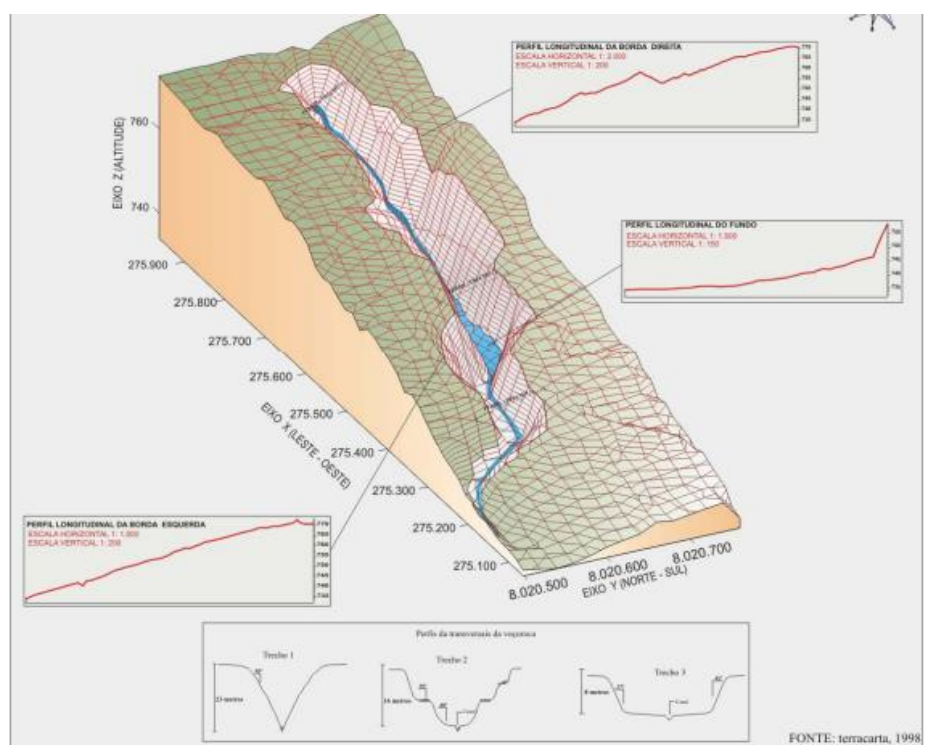

Figura 3. Croqui do cadastro da erosão em 1998. Fonte: Castro et al., 2004.

Os dados coletados com apoio do VANT, em outubro de 2016 (Figura 4), indicam que a voçoroca ainda apresenta formato suavemente meandrante para a porção sul, além de delineamento de curvas de nível e revegetação espontâneas. As intervenções físicas, associadas ao projeto de recuperação da erosão, vincularam-se ao isolamento da área, com construção de curvas de nível a montante da "cabeceira". O isolamento da área garantiu, ao longo de 16 anos, a revegetação espontânea de espécies típicas da fitofisionomia Cerrado Típico. 


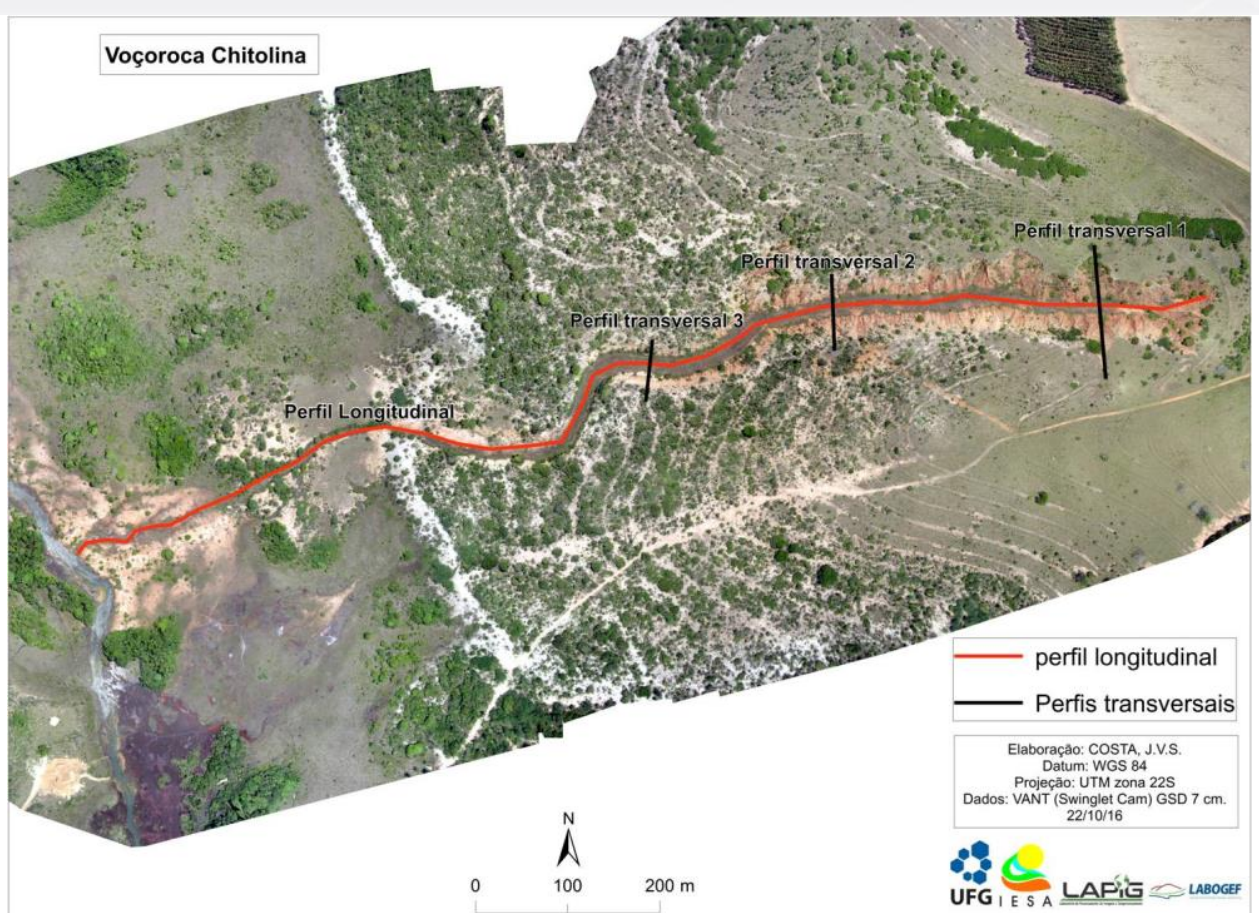

Figura 4 - Ortofoto da erosão Chitolina obtida com o VANT, sobreposta com perfis topográficos, com destaque para a recomposição espontânea da cobertura vegetal no seu trecho médio e o assoreamento a jusante (final do lado esquerdo da ortofoto).

As análises dos dados do sobrevoo indicam que a erosão apresenta em 2016: 1350 metros de eixo longitudinal (Figura 5A), 24 metros de profundidade máxima em sua "cabeceira" (Figura 5B); 14 metros em seu percurso médio (Figura 5C); média de 4 metros na sua trajetória final (Figura 5D).
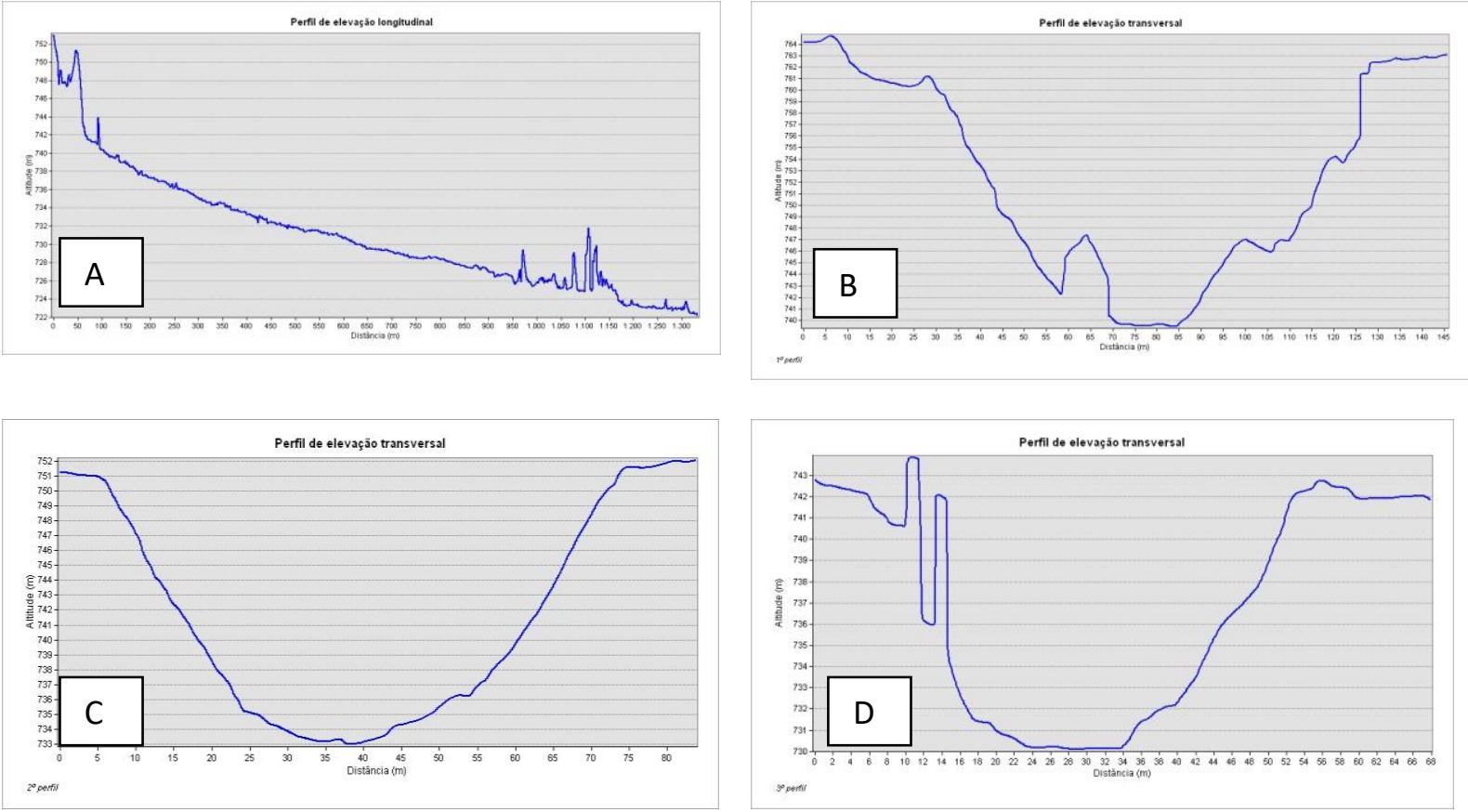

Figura 5 - Detalhe dos perfis. A- Perfil de elevação longitudinal; B - Perfil 1 transversal (profundidade máxima; C - Perfil 2 transversal (profundidade em percurso médio; D - Perfil 3 transversal na trajetória final. 


\section{OS DESAFIOS DA GEOGRAFIA FÍSICA NA FRONTEIRA DO CONHECIMENTO \\ Instituto de Geociências - Unicamp \\ Campinas - SP \\ 28 de Junho à 02 de Julho de 2017}

Para Gomes, Filizola e Boulet (S/D), entre 1995 e 2000 o processo erosivo avançou pouco longitudinalmente, estando possivelmente mais associado à presença de material argilo-arenoso no interior da erosão do que às curvas de nível instaladas a montante da área. No entanto, a forma meandrante na porção média e a abertura de ramificações laterais sobre solo de caraterísticas arenosas indicavam que a feição ainda continuava evoluindo.

As comparações entre as medições obtidas no cadastro e pelo levantamento do VANT indicam que a Chitolina encontra-se estabilizada nos últimos 30 anos, não apresentando crescimento longitudinal. No entanto, verifica-se no trecho médio o seu alargamento relacionado à presença de pipings, taludes rachados e/ou processo de desmoronamentos, os quais estão cedendo material para o entulhamento do processo erosivo (Figura 6). Este material está promovendo o assoreamento do canal de drenagem anteriormente presente na erosão; o interior da erosão apresenta-se revegetado com espécies graminosas e algumas espécies arbóreas.

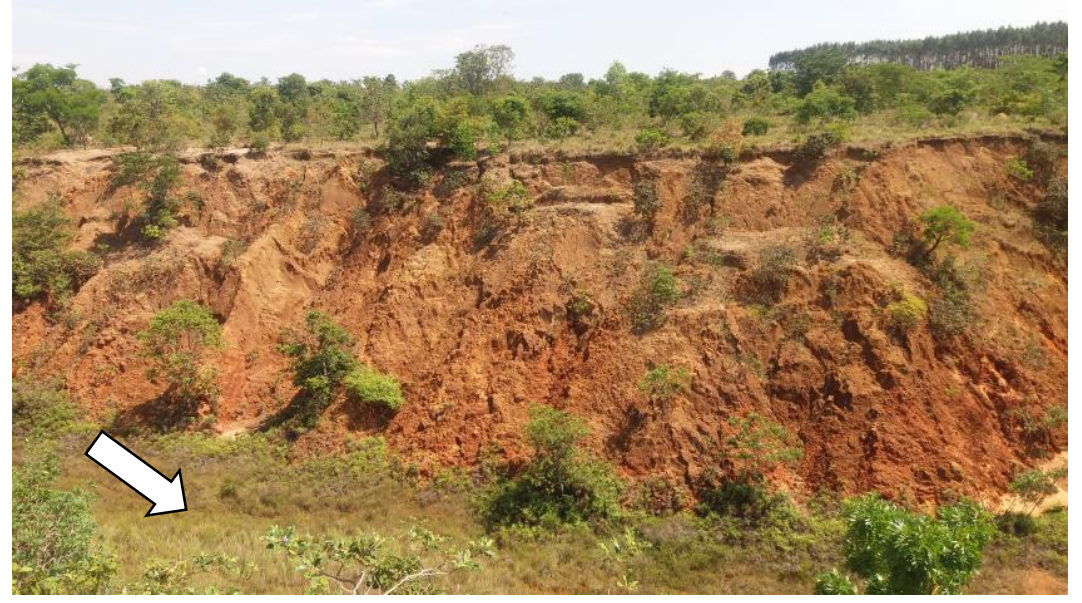

Figura 6 - Desmoronamentos de taludes. Seta indica interior da erosão em processo de revegetação espontânea em seu fundo. Fonte: Faria, out.2016.

As ramificações identificadas na década de 2000 não foram identificadas no sobrevoo com o VANT. A contenção do escoamento superficial por meio de curvas de nível e isolamento da área podem ter contribuído para a aparente estabilização do processo erosivo. No entanto, o cultivo da cana-de-açúcar a montante da erosão demanda monitoramento do comportamento do lençol freático, uma vez que a causa do desenvolvimento da erosão já foi associada a retroalimentação excessiva do lençol freático.

\section{Considerações Finais}

A avaliação da dinâmica da erosão Chitolina indica que o processo não evoluiu na útlima década, pois os dados obtidos com o VANT, associados a três décadas de levantamentos e estudos, indicam que o processo se apresenta estabilizado em nível longitudinal e as campanhas de campo constataram que 


\section{OS DESAFIOS DA GEOGRAFIA FÍSICA NA FRONTEIRA DO CONHECIMENTO \\ Instituto de Geociências - Unicamp \\ Campinas - SP \\ 28 de Junho à 02 de Julho de 2017}

apenas no setor médio há evolução dos taludes por desmoronamentos, conduzindo ao seu alargamento; entretanto, tais desmoronamentos estão provovendo o entulhamento do fundo e leito do foco erosivo.

A utilização do VANT mostrou-se útil por reduzir o tempo de cadastramento e custos no monitoramento do processo. Nesse sentido, as principais vantagens deste imageamento encontram-se na possibilidade de mensuração do foco erosivo em toda a sua extensão, na elaboração do MDS e MDT da área, na realização de perfis longitudinais e transversais do foco e na visão panorâmica da área afetada. Contudo, atividades de campo in loco ainda se fazem necessárias para avaliações e constatações particularizadas do processo, bem como para realização de ensaios e coleta de amostras.

Por fim, os resultados obtidos poderão ser utilizados para o monitoramento futuro do processo aqui relatado, bem como uma técnica para análise e recuperação desta e de outras erosões.

\section{Agradecimentos}

À CAPES, pelo apoio na aquisição do VANT junto ao Programa de Pós-Graduação em Geografia da Universidade Federal de Goiás (Pró-equipamentos 2012 e 2014). Ao WWF (Programa Ecodrones ), pelo apoio na manutenção do VANT. À Santiago \& Cintra, Sensefly e Pix4D, pela parceria com o LAPIG/UFG

\section{Bibliografia}

BOULET, R. (2001). Relatório de Consultoria referente à primeira fase dos estudos realizados para a recuperação da voçoroca Chitolina, município de Mineiros -GO (Julho 2000/março 2001) (entregue à Fundação Emas).

CABACINHA, C. D.;CASTRO, S. S. Relationships between floristic diversity and vegetation indices, forest structure and landscape metrics of fragments in Brazilian Cerrado. Forest Ecologyand Management, v. 257, p. 2157-2165, 2009.

CARVALHO, J.C.; Melo, M.T.S. A erosão à luz da legislação ambiental. Carvalho, J.C.; Sales, M.M.; Souza, N.M.; Melo, M.T.S., (org.). In: Processos erosivos no centro oeste brasileiro, Brasília, editora Finatec, 2006. P. 1-37.

CASTRO, S.S. Erosão hídrica na alta bacia do rio Araguaia: distribuição, condicionantes, origem e dinâmica atual. Revista do Departamento de Geografia, 17: 38-60, 2005.

CASTRO, S.S.; BARBALHO, M.G.S.; MARINHO, G.V.; CAMPOS, A.B.; SALOMÃO, F.X.T.; VECHIATTO, A. Condicionantes hidrológicos, geomorfológicos, pedológicos e de uso e manejo dos solos na circulação hídrica e processos de voçorocamento na alta bacia do rio Araguaia (GO/MT). In: COUTO, E. G.; BUENO, J. F. (Eds.). Os (Des) caminhos do uso da água na agricultura brasileira. Cuiabá: Ed. UFMT/SBCS, p.408-448.2004

CASTRO, S.S.; XAVIER, L.S. (2004) Plano de controle de erosão linear das nascentes dos rios Araguaia e Araguainha. SEMARH-GO. Projeto de Recomposição Ambiental das Nascentes do Araguaia. Goiânia (no prelo). CASTRO, S.S.; COOPER, M.; SANTOS, M.C.; VIDALTORRADO, P. (2003) Micromorfologia de solos: bases e aplicações. In: Tópicos em Ciência do Solo, 3, SBCS, Viçosa, v. 3: 107-164. 
OS DESAFIOS DA GEOGRAFIA FÍSICA NA FRONTEIRA DO CONHECIMENTO

Instituto de Geociências - Unicamp

Campinas - SP

28 de Junho à 02 de Julho de 2017

CASTRO, S.S.; XAVIER, L.S.; BARBALHO, M.G.S. Atlas Geoambiental das Nascentes do rio Araguaia e Araguainha. SEMARH-GO. Projeto de Recomposição Ambiental das Nascentes do Araguaia. Goiânia.2004

CENTRAIS ELÉTRICAS DE GOIÁS - CELG. Levantamento de campo para elaboração de projeto de recuperação das voçorocas. Rel. Técnico final do Projeto recuperação Ambiental das Nascentes do Araguaia. 1998.

D'OLEIRE-OLTMANNS, S. et AL. Unmanned Aerial Vehicle (UAV) for monitoring soil erosion in Morocco. Journal Remote Sensing, v. 4, p. 3390-3416, 2012.

FAO and ITPS.Status of the World's Soil Resources (SWSR) - Main Report.Food and Agriculture Organization of the United Nations and Intergovernmental Technical Panel on Soils, Rome, Italy, 2015.

FARIA, K. M. S. de; CASTRO, S. S. Uso da terra e sua relação com os remanescentes de cerrado na alta bacia do rio Araguaia (GO,MT e MS). Geografia (Rio Claro), v. 32, p. 657-668, 2007.

FUNDAÇÃO EMAS. Projeto Recomposição Ambiental das Nascentes do Araguaia, Mineiros, 1998, 4p

GOMES, M.A.F; FILIZOLA, H.F. BOULET, R. Gênese e evolução da voçoroca Chitolina. IN: http://www.agencia.cnptia.embrapa.br/gestor/agricultura_e meio_ambiente/arvore/CONTAG01_61_210200792 $\underline{814 . h t m l \text { acessado em } 30 \text { de outubro de } 2016 .}$

GUERRA A.J.T. O início do processo erosivo. In: GUERRA, A.J.T; SILVA, A. S; BOTELHO, R.G.M; (org.). Erosão e conservação dos solos conceitos, temas e aplicações. Rio de janeiro: Bertrand Brasil, 2005. P. 17-50.

HELFER, F; LOPES, F; RISSO, A; BELTRAME, L; MERTEN, G. Estimativa da perda de solo por erosão laminar na bacia hidrgráfica do rio Cuiabá usando técnicas de geoprocessamento. XV Simpósio Brasieiro de Recursos Hídricos. 2003

INFANTI, N.J; FORNASARI, N.F. Processos de dinâmica superficial. In: OLIVEIRA, A.M.S; BRITO; S.N.A (ed.). Geologia de engenharia. São Paulo, CNPQ e FAPESP, 1998. 131-136 p.

LEPSCH, I. F. Formação e conservação dos solos. São Paulo, editora Oficina de Textos, 2002. 177p.

MARTINS, E. O.; SOUZA, N. M. de.; SALES, M. M.; NASCIMENTO, M. A. L. S. do.; OLIVEIRA, M. de F. M. Cadastro de erosões. In: CAMAPUM de CARVALHO, J.; SALES, M. M.; SOUZA, N. M. de.; MELO, M. T. da. S. (Org.). Processos Erosivos no Centro-Oeste Brasileiro. Brasília: FINATEC, 2006. Cap. 5, p. 193220.

MOURA, I. B. ; SHIRAIWA, S. . Caracterização da superfície piezométrica em uma vertente na Alta Bacia do Rio Araguaia com métodos geofísicos. In: XIV Reunião Brasileira de Manejo e Conservação do Solo e da Água, 2002, Cuiabá. Resumos da XIV Reunião Brasileira de Manejo e Conservação do Solo e da Água. Cuiabá: EdUFMT, 2002. p. 33.

SALOMÃO, X. F. Controle e Prevenção dos Processos Erosivos. In: Guerra, A. T. Erosão e Conservação dos Solos: Conceitos, Temas e Aplicações. Rio de Janeiro, Bertrand do Brasil,1999.

SHIRAIWA, S. ; MOURA, I. B. ; PORSANI, J. L. . O uso do GPR para estudo de estruturas pedológicas de uma vertente relacionada com uma vossoroca na Alta Bacia do Rio Araguaia-GO. In: Eighth International Congress of The Brazilian Geophysical Society, 2003, Rio de Janeiro. Eighth International Congress of The Brazilian Geophysical Society - Anais. Rio de Janeiro: Sociedade Brasileira de Geofísica, 2003. p. 1-6.

SILVA R. A. A da. Arenização/Desertificação no Setor Sul da Alta Bacia do Rio Araguaia (GO/MT): distribuição e fatores condicionantes de formação dos areais. 2006. Dissertação (Mestrado em Geografia) Universidade Federal de Goiás, Goiânia.

SILVA, A.S.; BARBALHO, M.G.S.; CASTRO, S.S. Análise comparada de formas de ocorrências erosivas lineares utilizando diferentes resoluções com imagem Landsat TM 5 e 7. Anais do IX Simpósio Brasileiro de Geografia Física Aplicada, Recife. 2001

TRINDADE, S. P. Aptidão agrícola, mudanças de usos dos solos, conflitos e impactos diretos e indiretos da expansão da cana-de-açúcar na região sudoeste goiano. 2015. 187 f. Tese (Doutorado em Ciências Ambientais) Universidade Federal de Goiás, Goiânia. 